\title{
Effect of conjugated linoleic acid, vitamin $E$ and their combination on lipid profiles and blood pressure of Iranian adults with active rheumatoid arthritis
}

\author{
Naheed Aryaeian' \\ Farhad Shahram² \\ Mahmoud Djalali \\ Mohammad R Eshragian ${ }^{3}$ \\ Abolghasem Djazayeri' \\ Abdolfatah Sarrafnejad ${ }^{4}$ \\ Nasim Naderi ${ }^{2}$ \\ Maryam Chamari' \\ Fariha Fatehi' \\ Mahnaz Zarei' \\ 'Department of Nutrition and \\ Biochemistry, School of Public \\ Health and Institute of Public Health \\ Research, Tehran University of Medical \\ Sciences, Iran; ${ }^{2}$ Rheumatology \\ Research Center, Shariati Hospital, \\ Tehran University of Medical Sciences, \\ Iran; ${ }^{3}$ Department of Epidemiology \\ and Biostatistics, School of Public \\ Health and Institute of Public Health \\ Research, Tehran University \\ of Medical Sciences, Iran; ${ }^{4}$ Department \\ of Immunology, School of Public \\ Health and Institute of Public Health \\ Research, Tehran University \\ of Medical Sciences, Iran
}

\author{
Correspondence: Mahmoud Djalali \\ Department of Nutrition \\ and Biochemistry, School \\ of Public Health, Tehran University \\ of Medical Sciences, Iran \\ Tel +98 2l 889549 I I \\ Fax +98 21 88974462 \\ Email jalalimahmoud@hotmail.com
}

\begin{abstract}
The aim of this study was to assess the impact of conjugated linoleic acids (CLAs), vitamin E, and combination of these nutrients on serum lipid profiles and blood pressure (BP) in patients with active rheumatoid arthritis (RA). In a randomized, double-blind, placebo-controlled trial, 87 patients with active RA were divided into four groups receiving one of the following daily supplements for three months: Group C: CLAs $2.5 \mathrm{~g}$ equivalent to $2 \mathrm{~g}$ mixture of cis 9-trans 11 and trans 10-cis 12 CLAs in a rate of 50/50; Group E: vitamin E: $400 \mathrm{mg}$; Group CE: CLAs and vitamin $\mathrm{E}$ at above doses: Group P: placebo. After supplementation, SBP levels decreased significantly in the group $\mathrm{C}$ in comparison with groups $\mathrm{E}$ and $\mathrm{P}$ and mean arterial pressure reduced significantly in groups $\mathrm{C}$ and $\mathrm{CE}$. There weren't significant differences in the levels of prostaglandin E2 (PGE2), triglycerides, cholesterol, low-density lipoprotein cholesterol (LDL-C), high-density lipoprotein cholesterol (HDL-C), LDL/HDL, cholesterol/HDL, fasting blood sugar, C-reactive protein (CRP), arylestrase activity, platelet count and body mass index between groups. CRP dropped nonsignificantly in groups P, C, E and CE (19\%, 24\%, 55\%, and $39 \%$, respectively). Erythrocytes sedimentation rate levels decreased in groups $\mathrm{C}, \mathrm{E}$ and $\mathrm{CE}$ ( $P \leq 0.05, P \leq 0.05, P \leq 0.001$, respectively). It is concluded that supplementation of CLAs decreased BP and vitamin E decreased CRP. Therefore cosupplementation of CLAs and vitamin E might be profitable for heart disease prevention in RA patients.
\end{abstract}

Keywords: rheumatoid arthritis, lipid profiles, blood pressure, conjugated linoleic acids, vitamin $\mathrm{E}$

\section{Introduction}

Rheumatoid arthritis (RA), as the most common inflammatory disease, is associated with excess cardiovascular morbidity and mortality that is not entirely explained by traditional risk factors of cardiovascular disease (CVD) (De Pablo et al 2007). It might be due to an increased prevalence of cardiovascular risk factors such as dyslipidemia (Nurmohamed 2007). Risk factors for CVD, including inflammatory biomarkers, low intake of antioxidants, and vitamins, may contribute to excess CVD in persons with RA (Dessein et al 2006). There is a complex relationship between inflammation, antioxidant vitamin status, and the risk of CVD. Furthermore, low intakes of antioxidant vitamins and other micronutrients, including vitamin $\mathrm{E}$, have been reported to be inversely associated with CVD incidence and mortality (De Pablo et al 2007). Conjugated linoleic acids (CLAs) are a group of naturally occurring isomers of linoleic acid that differ in the position or geometry of their double bonds (Kelly 2001; Bhattacharya et al 2006). The biological activities of CLAs have received considerable attention because of its anticancer (Parodi 1999), antiatherogenic (Rudel 1999; Arbonés-Mainar et al 2006) and antidiabetic effects (Peck et al 1998). The atheroprotective properties of CLAs have been particularly well documented (Kritchevsky et al 2000; Toomey et al 2003). Inclusion of CLAs in a hypercholesterolemic diet in rabbits led to a significant 
reduction in serum triglyceride (TG), low-density lipoprotein cholesterol (LDL-C) and cholesterol (CHO) levels. In addition, there was a reduced incidence of atherosclerotic plaque formation in the rabbit aorta (Lee et al 1994). Similar results have also been reported for hamster hypercholesterolemia models (Nicolosi et al 1997; Wilson et al 2000). Despite these findings, some reports suggest that CLAs may possibly have proatherogenic effects (Munday et al 1999; Gavino et al 2000). There are several molecular mechanisms for explaining the hypotriacylglycerolemic effect of CLAs. The cis-9, trans-11 and the trans-10, cis-12 isomers of CLAs are potent peroxisome proliferators-activated receptor (PPAR) agonists. PPAR $\alpha$ is a key transcription factor that regulates hepatic lipid metabolism (Moya-Camarena and Belury 1999a). Feeding CLAs-enriched diets increases the expression of PPAR $\alpha$-responsive genes in animals (MoyaCamarena and Belury 1999b). Therefore, the TG-lowering effect of CLAs may be partly attributed to the effect of CLAs on PPAR $\alpha$. CLAs is also a PPAR $\gamma$ ligand. In adipose tissue, PPAR $\gamma$ regulates the expression of the genes that determine adipogenesis, lipid metabolism and insulin sensitivity (Lowell et al 1999; Moya-Camarena et al 1999). Some other proposed mechanisms include their role on peroxisome proliferators-sterol regulatory element-binding proteins (SREBPs) (Pai et al 1998) and stearoyl-CoA desaturase (SCD) (Miyazaki et al 2000, 2001; Ntambi 1999). SREBP1c isoforms regulate fatty acid and TG synthesis (Pai et al 1998). Studies suggest that liver SREBP-1c expression is dependent on the nuclear hormone liver $\mathrm{X}$ receptor (LXR). C9 $\mathrm{t} 11$ isomer was shown to down-regulate mRNA expression of LXR- $\alpha$ and SREBP-1c, whereas the 110 c12 isomer had no effect (Roche et al 2002). The results suggested that c9t11 isomer positively influences lipid metabolism by reduced synthesis and cleavage of hepatic SREBP-1, which in turn is regulated by LXR $\alpha$ expression. SREBP-1c enhances the transcription of the genes required for fatty acid synthesis and fatty acid elongation including fatty acids synthetase (FAS) and SCD (Pai et al 1998; König et al 2008). Hypertension is also a common pathological state associated with an increased risk of cardiovascular diseases. Some studies have shown that CLAs (50:50) or the $110 \mathrm{c} 12$ isomer decreases blood pressure (BP) and hypertension in various rat models prone to develop obesity, diabetes and hypertension (Nagao et al 2003a, 2003b; Alice et al 2005). One possible mechanism is through inhibition of cyclooxygenases, both of them have been implicated in the development of atherosclerosis (Belton et al 2003). c9, t11- and t10, c12-CLAs isomers are not substrates for cyclooxygenases (COX) but compete with arachidonic acid for access to the enzymes. In one study, it was seen that feeding rabbits with an atherogenic diet rich in CLAs reduced atherosclerotic lesion sizes (Valetille et al 2005). A number of studies in rabbits have considered the potential for the lipophilic antioxidant vitamin $\mathrm{E}$ to inhibit atherosclerosis in vitro by decreasing lipid peroxidation of LDL (Schwenke et al 1998). Some epidemiological studies have shown an association between high dietary intake and high serum concentrations of vitamin $\mathrm{E}$ and lower rates of ischemic heart disease (Gey et al 1990; Rimm et al 1993; Stampfer et al 1993) and myocardial infarction (Stephens et al 1996). Here, we investigated the effect of 50:50 blend of $c 9, t 11: t 10, c 12$-CLAs on BP and lipid profiles in active RA patients.

\section{Materials and methods}

\section{Subjects}

A randomized double blind placebo controlled trial was conducted in a 12 week period in 87 patients with active RA. Patients were between 19-69 years old and had RA for at least 2 years fulfilling American College of Rheumatology (ACR) criteria of 1987 (Arnett et al 1988). The method for evaluation of disease activity was global physician assessment (GPA). Disease activity was determined by rheumatologist by medical history, pain in joints, morning stiffness, inflammation and tenderness and by acute phase reactants such as C-reactive protein (CRP), erythrocytes sedimentation rate (ESR), platelet (PLT), and hemoglobin ( $\mathrm{Hb})$. Data on dietary habits, dietary supplements, anthropometric indices including body mass index (BMI), smoking habits, and drug history were obtained by face to face interview. The exclusion criteria were: abnormal renal and/or hepatic function, smoking, and history of myocardial infarction, pregnancy, taking vitamins and/or mineral supplements, hyperlipidemia and taking drugs such as thyroid hormones, estrogens, progesterone, diuretics or $\beta$-blockers. A written informed consent was obtained from all participants. The research protocol was approved by the Ethics Committee of Tehran University of Medical Sciences. The patients were divided into four groups to receive randomly either CLAs (group C), vitamin E (group E), both CLAs and vitamin E (group CE) or placebo (group P). CLAs was prescribed $2 \mathrm{~g}$ daily as 2 capsules (each capsule was $1.25 \mathrm{~g}$ and contained $80 \%$ CLAs) containing both cis-9, trans-11 CLAs and trans-10, cis-12 triglyceride type CLAs in equal proportion and vitamin $\mathrm{E}$ ( $\alpha$-tocopherol, $400 \mathrm{mg}$ ). Corn oil was the placebo for vitamin $\mathrm{E}$ and high oleic sunflower (HOSF) was placebo for CLAs. These were assigned to one of the four 
treatment groups using random permuted blocks procedure. The amount of nutrients intakes were estimated using a 24-hour dietary recall questionnaire for two following days before and after the study and analyzing by Food Processor software (ESHA Research, Salem, OR).

The subjects were asked not to alter their usual diets and physical activity throughout the study and any changes in their medication were avoided whenever possible and if the patients did change their nonsteroidal anti-inflammatory drug (NSAIDs) intake they must write it in the special forms provided. Compliance with the supplementation was assessed by counting the number of capsules used and also by measuring changes in the serum vitamin $\mathrm{E}$.

After $12-14 \mathrm{~h}$ overnight fasting, $10 \mathrm{ml}$ blood samples were collected from each subject at the beginning and at the end of the three month trial.

\section{Methods}

Blood samples were collected in trace element-free tubes. Aliquots of serum were transferred to polystyrene tubes which were immediately stored at $-70{ }^{\circ} \mathrm{C}$ until analysis. Prostaglandin E2 (PGE2) was measured by ELISAMonoclonal Kit (No 514010.1; Cayman Chemical Co, Ann Arbor, MI). Plasma CHO and TG concentrations were determined by an enzymatic assay adapted to microtiter plates using commercially available kits (Randox Labs, Crumlin, North Ireland). High-density lipoprotein cholesterol (HDL-C) was determined by Immunoinhibition Colorimetric method (EliTech, Seppim SAS Industrial, Sees, France). LDL-C was measured by enzymatic colorimetric method (EliTech, Seppim SAS Industrial). Fasting blood sugar (FBS) was measured by enzymatic colorimetric method (colorimetric). CRP values were determined with immunoturbidometric assay. In this method CRP gives a complex with polyclonal antibody and creates turbidity that has positive relation with CRP in sample. Arylestrase activity (AEA) was measured by phenylacetate that was used as a substrate to measure the AEA. Enzymatic activity was calculated from the molar absorptive coefficient of the produced phenol, one unit of AEA was defined as $1 \mathrm{mmol}$ phenol generated per min under the above conditions and expressed as units/l of serum (Kushi et al 1996). Serum $\alpha$-tocopherol was determined by high performance liquid chromatography (Sanz and SantaCruz 1986). Hematological analyses were counted by an automated blood counter (Beckman Coulter, Miami, FL). ESR was measured using an ESR apparatus (Greiner Labor Technic GmbH, Germany). The systolic (SBP) and diastolic blood pressure (DBP) was measured after five minutes seated rest, the mean of two readings at baseline, and after three months of supplementation. Mean arterial pressure (MAP) was calculated using this formula $(\mathrm{SBP}+2 \mathrm{DBP}) / 3$ (Cywinski 1980).

\section{Statistical analysis}

All values are expressed as mean \pm standard error of mean. Log transformation was used to normalize the distribution of CRP. All other variables were normally distributed. Differences between four groups were compared by one-way analysis of variance (ANOVA) for continuous data and the $\chi 2$-test for categorical data. Post hoc comparisons were performed with Tukey test. Adjustment for differences in baselines covariates and changes in variables during study were performed by analysis of covariance. A value of $\mathrm{P} \leq 0.05$ was considered to be statistically significant. All data were analyzed using SPSS software (SPSS Inc., Chicago, IL).

\section{Results}

As shown in Table 1, groups were similar with respect to the sex, age, duration of RA, BMI, and daily intake of vitamin E at the beginning of the study. There were no significant changes in BMI, physical activity, dietary intake or medication during the study period (data not shown).

Table 2 shows the serum lipid, lipoprotein concentrations and BP before and after supplementation for subjects who completed the study. At baseline there were no significant differences between groups by ANOVA. Our study did not show any significant changes in plasma CHO or LDL-C concentrations in $\mathrm{C}$ and $\mathrm{CE}$ groups following three months of supplementation. Plasma levels of HDL-C increased nonsignificantly in the groups $\mathrm{P}, \mathrm{C}, \mathrm{E}$, and $\mathrm{CE}$ by $0.9 \%$, $1.23 \%, 2.35 \%$, and $4.9 \%$, respectively as compared with baseline. LDL-C increased in all groups, but this increase was significant in group E compared with baseline. We did not find any significant change in HDL-C and LDL-C concentrations among four groups. Total $\mathrm{CHO}, \mathrm{CHO} / \mathrm{HDL}-\mathrm{C}$ and LDL-C/ HDL-C ratios, and TG were not altered significantly after supplementation compared with baseline and between four groups. After three months of supplementation in the group $\mathrm{C}$, SBP levels reduced significantly by $8 \%(117.36 \pm 3.80 \mathrm{mmHg}$ versus $108.04 \pm 3.13 \mathrm{mmHg})(\mathrm{P}<0.05)$ and $\mathrm{DBP}$ by $8.5 \%$ $(72.36 \pm 2.37 \mathrm{mmHg}$ versus 66.14 $\pm 1.66 \mathrm{mmHg})(\mathrm{P}<0.05)$. The MBP decreased as compared with baseline in groups $\mathrm{C}$ and $\mathrm{CE}, 8.3 \%$ and $5.66 \%$, respectively (Figure 1). The reduction of SBP in group $\mathrm{C}$ was significant compared with other groups $(P<0.05)$ (Figure 1$)$. 
Table I Demographic, anthropometric and biological data for the four groups before study (Mean \pm SEM)

\begin{tabular}{lllll}
\hline Variables & Placebo $(\mathbf{n}=\mathbf{2 2})$ & Conjugated linoleic acids $($ CLAs) $(\mathbf{n}=\mathbf{2 2})$ & Vitamin E $(\mathbf{n}=\mathbf{2 1})$ & CLAs + vitamin E $(\mathbf{n}=\mathbf{2 2})$ \\
\hline Male/Female & $3 / 19$ & $3 / 19$ & $4 / 17$ & $5 / 17$ \\
Age (years) & $47.95 \pm 2.37$ & $46.23 \pm 2.79$ & $49.33 \pm 2.59$ & $43.77 \pm 12.75$ \\
Duration of & $8.89 \pm 2.06$ & $9.95 \pm 1.79$ & $7.24 \pm 1.27$ & $7.64 \pm 1.32$ \\
RA $($ years) & & & & $25.65 \pm 0.85$ \\
BMl $\left(\mathrm{kg} / \mathrm{m}^{2}\right)$ & $28.48 \pm 0.84$ & $27.18 \pm 0.99$ & $27.14 \pm 1.03$ & $8.80 \pm 0.76936$ \\
Vitamin E intake & $7.9 \pm 0.53188$ & $8.75 \pm 0.51723$ & $7.78 \pm 0.78260$ & \\
(mg per day) & & & & \\
\hline
\end{tabular}

Note: There were no significant differences between groups by ANOVA or Chi-square.

Abbreviation: BMI, body mass index.

Table 3 shows the serum PGE2, FBS, CRP concentrations, AEA, ESR, WBC, PLT, and BMI before and after supplementation for subjects who completed the study. At baseline there were no significant differences between groups by ANOVA. PGE2 didn't alter significantly among groups and in each group as compared with baseline $(P>0.05)$. ESR levels decreased significantly in groups $\mathrm{C}, \mathrm{E}$, and $\mathrm{CE}(\mathrm{P} \leq 0.05, \mathrm{P} \leq 0.05$, $\mathrm{P} \leq 0.001$, respectively) in comparison with baseline and group CE had significantly lower ESR level than group $\mathrm{P}(\mathrm{P} \leq 0.05)$. CRP decreased nonsignificantly in all groups as compared with baseline, after three months of supplementation (Figure 2), but this reduction was $55 \%$ in group E compared with baseline $(\mathrm{P}=0.054)$. The reduction of $\mathrm{WBC}$ in group $\mathrm{CE}$ was significant compared with other groups $(P<0.05)$ (Table 3$)$. Platelet count decreased nonsignificantly in groups $\mathrm{CE}, \mathrm{C}$, and $\mathrm{E}$. BMI and
FBS changes weren't significance in all groups. AEA decreased nonsignificantly in Groups E, $\mathrm{C}$, and $\mathrm{P}(P \geq 0.05)$ and there weren't significant differences between 4 groups. Following the study Serum levels of $\alpha$-tocopherol increased significantly in groups $\mathrm{C}, \mathrm{E}$ and $\mathrm{CE}$ as compared with baseline $(P \leq 0.05$, $P \leq 0.0001, P \leq 0.0001$, respectively) and in groups $\mathrm{E}$ and CE compared with group $\mathrm{P}(P \leq 0.0001)$.

\section{Discussion}

In RA disease, chronic systemic inflammation may contribute to the higher incidence of CVD. (Hannawi et al 2007; Metosios et al 2007). To our knowledge; this is the first study which investigated the effects of CLAs and its combination with vitamin $\mathrm{E}$ in human with RA disease. In the present study, we didn't find any significant changes in the plasma

Table 2 Levels of lipid profile and blood pressure variables in patients with active rheumatoid arthritis before and after three months supplementation (Mean \pm SEM)

\begin{tabular}{|c|c|c|c|c|c|}
\hline Variables & & Placebo $(n=22)$ & $\begin{array}{l}\text { Conjugated linoleic } \\
\text { acids (CLAs) }(n=22)\end{array}$ & $\begin{array}{l}\text { Vitamin E } \\
(n=2 I)\end{array}$ & $\begin{array}{l}\text { CLAs + Vitamin } \\
\text { E }(\mathbf{n}=\mathbf{2 2})\end{array}$ \\
\hline \multirow[t]{2}{*}{ TG (mg/dl) } & before & $120.45 \pm 1 \mid .5$ & $118.45 \pm 9.83$ & $120.86 \pm 9.34$ & $|25.9| \pm 9.08$ \\
\hline & after & $124.9 \mid \pm 13.03$ & $130.4 \pm 18.32$ & $132.47 \pm 15.07$ & $126.18 \pm 14.28$ \\
\hline \multirow[t]{2}{*}{$\mathrm{CHO}(\mathrm{mg} / \mathrm{dl})$} & before & $191.32 \pm 9.04$ & $187.05 \pm 7.94$ & $191.76 \pm 10.68$ & $197.68 \pm 8.96$ \\
\hline & after & $198.27 \pm 10.56$ & $189.4 \pm 9.04$ & $201.76 \pm 8.82$ & $193.86 \pm 8.92$ \\
\hline \multirow[t]{2}{*}{ LDL-C (mg/dl) } & before & $104.14 \pm 5.48^{e}$ & $102.32 \pm 4.43$ & $103.43 \pm 5.5 I^{a}$ & $106.36 \pm 6.65$ \\
\hline & after & $114.86 \pm 7.47$ & $107.05 \pm 5.00$ & $114.85 \pm 6.17$ & $113.50 \pm 6.89$ \\
\hline \multirow[t]{2}{*}{ HDL-C (mg/dl) } & before & $49.50 \pm 1.94$ & $47.77 \pm 2.36$ & $50.38 \pm 2.79$ & $47.18 \pm 2.31$ \\
\hline & after & $49.95 \pm 2.26$ & $48.36 \pm 2.06$ & $51.57 \pm 1.89$ & $49.50 \pm 2.04$ \\
\hline \multirow[t]{2}{*}{ LDL/HDL } & before & $2.14 \pm 0.12^{f}$ & $2.19 \pm 0.094$ & $2.12 \pm 0.12$ & $2.37 \pm 0.19$ \\
\hline & after & $2.37 \pm 0.17$ & $2.33 \pm 0.12$ & $2.26 \pm 0.12$ & $2.32 \pm 0.13$ \\
\hline \multirow[t]{2}{*}{$\mathrm{CHO} / \mathrm{HDL}$} & before & $3.93 \pm 0.19$ & $3.99 \pm 0.14$ & $3.88 \pm 0.19$ & $4.36 \pm 0.26^{c}$ \\
\hline & after & $4.08 \pm 0.23$ & $4.03 \pm 0.20$ & $3.89 \pm 0.19$ & $3.97 \pm 0.17$ \\
\hline
\end{tabular}

Notes: There were no significant baseline differences between groups by ANOVA. Statistically significant differences between before and after: $\mathrm{P} \leq 0.05$. Statistically non significant differences between before and after: ${ }^{c} P=0.072$. Statistically no significant differences between before and after: ${ }^{e} P=0.086$. Statistically no significant differences between before and after: $\mathrm{f}=0.065$.

Abbreviations: CHO, cholesterol; HDL-C, high-density lipoprotein-cholesterol; LDL, low-density lipoprotein-cholesterol; TG, triglycerides. 


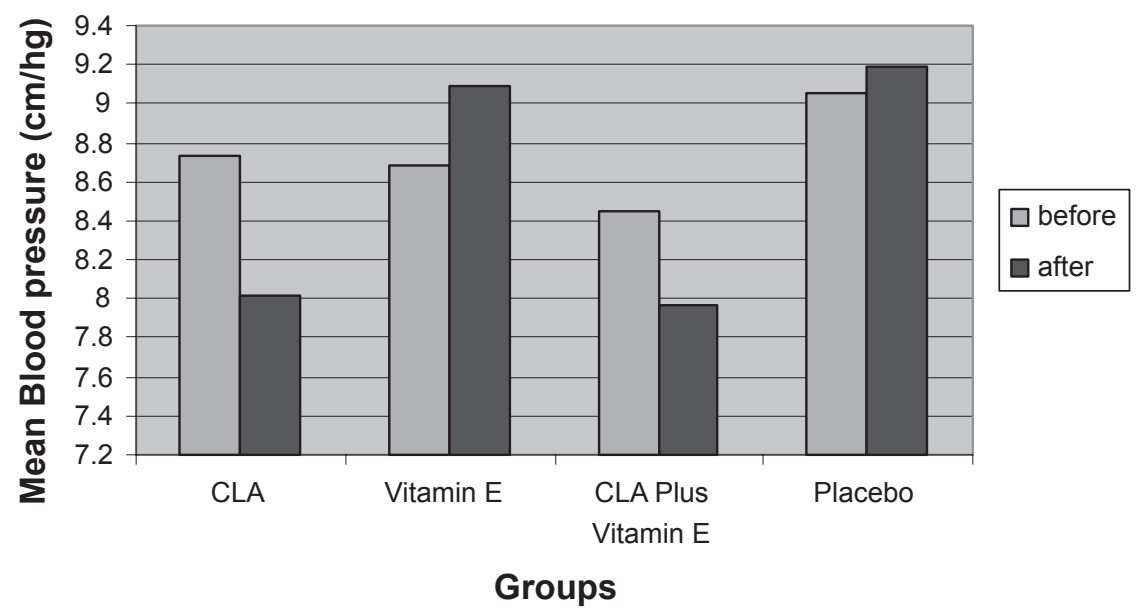

Figure I Levels of mean arterial pressure before and after three months' vitamin E and conjugated linoleic acid (CLA) supplementation in patients with active rheumatoid arthritis.

Note: $* \mathrm{p} \leq 0.05$ for CLA group compared with baseline and group P.

levels of TG and CHO in any of the studied groups. The magnitude of the change in plasma TG concentrations in our study is comparable with that achieved following 50:50 CLAs supplementation in Benito and colleagues' (2001) study. They did not find any effect on plasma CHO, lipoprotein, or TG. Noone and colleagues' (2002) study did not show any modification of plasma $\mathrm{CHO}$ and lipoprotein concentrations in healthy subjects receiving the 50:50 CLAs mix, however they showed a decrease in the TG concentration. Some other studies showed that trans-10, cis-12 CLAs isomer may be the effective hypotriglycerolemic isomer (Gavino et al 2000; Lin et al 2001). The TG-lowering effect of CLAs may be partly attributed to the effect of CLAs on PPAR $\alpha$. Furthermore, CLAs is a PPAR $\gamma$ ligand. In adipose tissue, PPAR $\gamma$ regulates the expression of the genes that determine adiposeness, lipid metabolism, and insulin sensitivity (Houseknecht et al 1998; Lowell 1999). In our study, there was a nonsignificant decrease in CHO in CE group. We used CLAs capsules with equal proportions of the cis-9, trans-11 and trans-10, cis-12 CLAs in triglyceride form. Recent vitro and

Table 3 Levels of blood pressure, oxidative stress variables in patients with active rheumatoid arthritis before and after three months supplementation (Mean \pm SEM)

\begin{tabular}{|c|c|c|c|c|c|}
\hline Variables & & Placebo $(n=22)$ & $\begin{array}{l}\text { Conjugated linoleic } \\
\text { acids (CLAs) }(n=22)\end{array}$ & $\begin{array}{l}\text { Vitamin E } \\
(n=2 I)\end{array}$ & $\begin{array}{l}\text { CLAs + Vitamin } \\
\text { E }(\mathbf{n}=22)\end{array}$ \\
\hline \multirow[t]{2}{*}{ Mean blood pressure $(\mathrm{mmHg})$} & Before & $90.54 \pm 3.03$ & $87.36 \pm 2.64^{\mathrm{a}}$ & $86.81 \pm 2.73$ & $84.50 \pm 2.48$ \\
\hline & After & $91.89 \pm 3.06$ & $80.10 \pm 1.93$ & $90.89 \pm 3.52$ & $79.71 \pm 2.36$ \\
\hline \multirow[t]{2}{*}{ Min blood pressure $(\mathrm{mmHg})$} & Before & $74.72 \pm 3.11$ & $72.36 \pm 2.37^{\mathrm{a}}$ & $71.81 \pm 2.62$ & $70.32 \pm 2.39$ \\
\hline & After & $75.72 \pm 2.78$ & $66.14 \pm 1.66$ & $75.24 \pm 2.95$ & $65.27 \pm 2.37$ \\
\hline \multirow[t]{2}{*}{ Max blood pressure $(\mathrm{mmHg})^{\dagger}$} & Before & $122.18 \pm 3.67$ & $117.36 \pm 3.80^{\mathrm{a}}$ & $116.8 \pm 3.83$ & $113.32 \pm 3.25$ \\
\hline & After & $124.68 \pm 4.19$ & $108.04 \pm 3.13$ & $122.2 \pm 5.52$ & $108.59 \pm 2.97$ \\
\hline \multirow[t]{2}{*}{ Aryl esterase activity (IU/ml) } & Before & $155.05 \pm 10.68$ & $159.45 \pm 10.12$ & $152.76 \pm 8.47$ & $146.77 \pm 8.23$ \\
\hline & After & $147.64 \pm 8.02$ & $157.55 \pm 11.58$ & $140.14 \pm 7.23$ & $|48.14 \pm 1| .5 \mid$ \\
\hline \multirow[t]{2}{*}{ PGE2 } & Before & $607.91 \pm 22.76$ & $623.27 \pm 21.87$ & $593.81 \pm 23.99$ & $620.04 \pm 20.34$ \\
\hline & After & $607.82 \pm 18.08$ & $613.45 \pm 92.06$ & $577.47 \pm 18.49$ & $605.04 \pm 18.53$ \\
\hline \multirow[t]{2}{*}{ Serum vitamin $E(\mu g / m l)$} & Before & $4.83 \pm 0.81$ & $4.72 \pm 0.94^{a}$ & $5.24 \pm 0.63 \mathrm{~b}^{\ddagger}$ & $6.64 \pm 0.99 b^{\psi}$ \\
\hline & After & $5.03 \pm 0.79$ & $5.51 \pm 0.95$ & $6.63 \pm 0.92$ & $7.78 \pm 0.98$ \\
\hline
\end{tabular}

Notes: There were no significant baseline differences between groups by ANOVA. Statistically significant differences between before and after: ${ }^{\mathrm{P}} \mathrm{P} \leq 0.05$; ${ }^{\mathrm{b}} \mathrm{P} \leq 0.00 \mathrm{I}$, after supplementation; ${ }^{\dagger}$ Group $C$ had significantly lower levels than group $P$ and $E(P \leq 0.05)$; ${ }^{\star} E$ Group had significantly higher levels than $P$ group $(P \leq 0.01)$. ${ }^{\psi} C E$ Group had significantly higher levels than $\mathrm{P}$ group $(\mathrm{P} \leq 0.05)$.

Abbreviation: PGE2. 


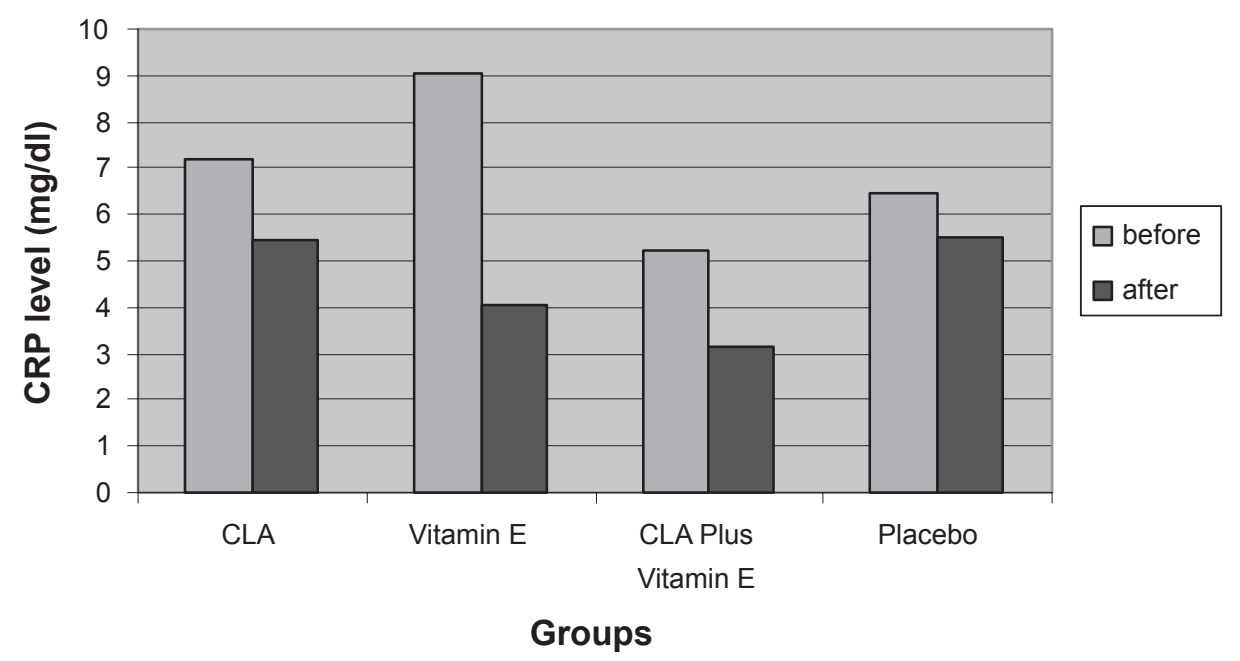

Figure 2 Levels of C-reactive protein (CRP) before and after three months vitamin E and conjugated linoleic acid (CLA) supplementation in patients with active rheumatoid arthritis.

animal studies suggest that the individual CLAs isomers may have different effects on lipid metabolism. Human studies regarding CHO-related parameters were not in line with the animal ones. The inconsistency of results may arise from the effects of particular CLAs consists the usual CLAs mix. Moreover, the dose of CLAs mix administered to humans, on a weight basis, was much lower than that for animal models and may not reach the effective level (Smedman and Vessby 2001). However, the effects of the CLAs-enriched dairy products on blood lipids were more complex. In our study similar to Desroches and colleagues' (2005) study after the consumption of the CLAs supplements, LDL-C, and HDL-C concentrations and the ratio of total to HDL-C and LDL-C to HDL-C were not significantly changed. Singhal and colleagues (2001) study results in patients with coronary heart disease were similar to our study and plasma TG concentration didn't change significantly in the vitamin E-supplemented group. A large base of epidemiological evidence suggests that a $1 \mathrm{mg} / \mathrm{dl}$ increment in HDL-C would be associated with a $2 \%-3 \%$ decrement in CVD risk (Gordon et al 1989). Our data show that supplementation of vitamin $E$ and its combination with CLAs for at least three months can increase HDL-C nonsignificantly by $3.4 \%$ and $4.5 \%$, respectively. Separate supplementation of CLAs did not improve serum HDL-C levels. The absence of such effects of CLAs supplementation should not be attributed to the interference of weight, physical activity, dietary intake or medication because these variables did not change during the study period and the patients had good compliance in taking their supplements. $\alpha$-Tocopherol possibly has power to inhibit oxidation induced by $\alpha$-tocopheroxyl radical (Singh et al 2005) and known synergistic action between vitamin $\mathrm{E}$ and CLAs (Kim et al 2005; Santoz-Zago et al 2007). Other studies have also shown that CLAs supplementation had no effect on HDL lipid composition (Nicolosi et al 1997; Gavino et al 2000; Stangl 2000). In our study, LDL-C increased in all groups and the difference between groups was not significant. Nicolosi and colleagues (2004) also showed that non-HDL-C concentrations were reduced by $(9 \%-13 \%)$ in response to a CLAs-enriched diet. The LDL-C/HDL-C was reduced in the 80:20 CLAs group (27.2\%) and the 50:50 CLAs group (22.4\%), however these weren't significant (Nicolosi et al 2004). In our investigation, CLAs plus vitamin E was more effective than CLAs in reducing LDL-C/HDL-C, CHO/ HDL-C, and CRP. In the present study, FBS didn't change significantly in four groups. Few studies have evaluated the effect of CLAs intake on glucose metabolism and insulin sensitivity in humans, but the available data suggest that glucose metabolism may be negatively affected by CLAs isomers. In Riserus and colleagues' (2001) study, a significant increase in glucose levels was observed in both the CLAs and the control group. The increase was more pronounced in the control group (Riserus et al 2001). In another study, glucose levels increased significantly only in the group receiving the trans 10 cis 12 isomer and not in the case of a mixture of different isomers. The increase was not significantly different from that which occurred in the control group (Riserus et al 2002). Smedman and Vessby (2001) also showed an increase $(p=0.054)$ in glycemia after the consumption of a mixture of CLAs isomers compared with the control group. They observed that insulin levels tended to increase after an intake of $2 \mathrm{~g}$ CLAs (Smedman and Vessby 2001). Several 
other studies have shown no deleterious effects on glucose or insulin levels or sensitivity to insulin attributable to the consumption of different doses of CLAs enriched with cis 9 , trans 11 or trans 10, cis 12 (Tricon et al 2004; Taylor and Zahradka 2004). Results on the effect of CLAs on glucose metabolism from animal studies are controversial (Houseknecht et al 1998; Stangl 2000; Tsuboyama-Kascoke et al 2000). In our study, CLAs supplementation had no effect on body weight. This finding is in agreement with Zambell and colleagues (2000) who found no changes in body weight or body composition attributed to CLAs supplementation in human subjects. However some studies have reported that CLAs supplementation ( $4 \mathrm{~g} / \mathrm{d}$ ) had no effect on body weight, but they significantly reduced body fat (Smedman and Vessby 2001). It was shown that, 9c, 11t-CLAs, 10t, 12c-CLAs inhibited arachidonic acid and collagen-induced platelet aggregation (Truitt et al 1999). In the present study, the number of platelet decreased nonsignificantly in groups $\mathrm{P}$, C, and CE. Leonard and colleagues (2007) studied the effects of vitamin E (400 IU) on cholesterol levels of hypercholesterolemic patients receiving statins. Similar to our study they didn't find significant differences in any lipoprotein cholesterol fraction. However, unlike our study, a $6 \%$ decrease in HDL-C was detected within the vitamin E group $(\mathrm{p}<0.05)$ (Leonard et al 2007). Following our study, LDL-C increased in all groups, but this increase was only significant in group $\mathrm{E}$. This increase may be due to increasing the size of LDL-C or changing its fractions or by increase of its half life by decreasing LDL-C oxidation. In our study AEA, decreased nonsignificantly in groups $\mathrm{E}, \mathrm{P}$, and $\mathrm{C}$, but decreased as compared with baseline in group $\mathrm{E}(\mathrm{P}=0.068)$. We had nonsignificant differences between four groups. In one study on pedigreed baboons, dietary vitamin E improved LDL quality and showed two apparently paradoxical effects on HDL metabolism: lower HDL2 and higher apo A-I. These effects have contrasting associations with CVD risk and may help account for the mixed results from clinical trials of dietary vitamin E. In our study, nonsignificant reductions in serum AEA of lipoprotein-associated enzymes, Paraxonase1 (PON1) in all groups except group CE was shown. The presence of PON1 on HDL particles is considered to be a major source of protection from lipoprotein oxidation. Therefore, reduction of PON1 activity may be considered to be prooxidant and proatherogenic (Rainwater et al 2007). Our results contradict results in rabbits and humans (Jarvik et al 2002; Jeon et al 2005). This discrepancy may reflect differences in HDL size and composition properties among the species. Alternately, vitamin E-associated reduction in oxidative stress and oxidized LDL may have lowered the metabolic requirements for these enzymes to maintain the redox balance in the circulation. Then, through feedback mechanisms, the expression of PON1 may have been downregulated (Jarvik et al 2003; Rainwater et al 2005). Furthermore the differences between groups wasn't significant. Following of our study

Table 4 Levels of FBS, inflammation variables and clinical tests in patients with active RA before and after three months supplementation (Mean \pm SEM)

\begin{tabular}{|c|c|c|c|c|c|}
\hline Variables & & Placebo $(n=22)$ & $\begin{array}{l}\text { Conjugated linoleic acids } \\
\text { (CLAs) }(n=22)\end{array}$ & $\begin{array}{l}\text { Vitamin E } \\
(n=21)\end{array}$ & $\begin{array}{l}\text { CLAs + vitamin } \\
\text { E }(n=22)\end{array}$ \\
\hline \multirow[t]{2}{*}{ CRP (mg/l) } & Before & $6.44 \pm 1.68$ & $7.18 \pm 2.16$ & $9.06 \pm 3.12$ & $5.23 \pm 1.37$ \\
\hline & After & $5.48 \pm 1.19$ & $5.46 \pm 1.18$ & $4.07 \pm 0.99$ & $3.17 \pm 0.83$ \\
\hline \multirow[t]{2}{*}{ ESR $(\mathrm{mm} / \mathrm{h})$} & Before & $28.36 \pm 4.59$ & $26.8 \mathrm{I} \pm 2.38^{\mathrm{a}}$ & $40.43 \pm 5.72^{\mathrm{a}}$ & $28.45 \pm 3.68 \ddagger^{c}$ \\
\hline & After & $27.04 \pm 4.04$ & $19.14 \pm 2.16$ & $32.28 \pm 5.01$ & $17.77 \pm 2.60$ \\
\hline \multirow[t]{2}{*}{ FBS (mg/dl) } & Before & $90.18 \pm 6.41$ & $78.27 \pm 1.95$ & $90.85 \pm 8.51$ & $85.68 \pm 6.15$ \\
\hline & After & $85.04 \pm 5.46$ & $75.86 \pm 1.41$ & $78.05 \pm 2.4 I$ & $81.85 \pm 3.14$ \\
\hline \multirow[t]{2}{*}{ WBC (/UL) } & Before & $8587.72 \pm 483.94$ & $7728.57 \pm 551.24$ & $7724.76 \pm 400.36$ & $9280.95 \pm 513.42^{\mathrm{a}}$ \\
\hline & After & $7752.95 \pm 457.03$ & $8533.33 \pm 401.86$ & $10276.2 \pm 2373.9$ & $8528.57 \pm 491.99$ \\
\hline \multirow{2}{*}{$\begin{array}{l}\text { Platelet count } \\
(* 1000 / \mathrm{UL})\end{array}$} & Before & $269.07 \pm 16.55$ & $294.38 \pm 12.49$ & $300.57 \pm 15.85$ & $294.14 \pm 16.95$ \\
\hline & After & $278.13 \pm 13.77$ & $286.09 \pm 13.98$ & $279.86 \pm 18.34$ & $280.09 \pm 14.96$ \\
\hline \multirow[t]{2}{*}{ BMI $\left(\mathrm{kg} / \mathrm{m}^{2}\right)$} & Before & $27.92 \pm 0.78$ & $26.95 \pm 0.94$ & $27.14 \pm 1.03$ & $25.65 \pm 0.85$ \\
\hline & After & $28.66 \pm 0.84$ & $27.41 \pm 4.49$ & $27.97 \pm 1.05$ & $25.94 \pm 0.76$ \\
\hline
\end{tabular}

Notes: There were no significant baseline differences between groups by ANOVA. Statistically significant differences between before and after: ${ }^{\text {a }} \mathrm{P} \leq 0.05 ; \mathrm{P} P \leq 0.0 \mathrm{I} ;{ }^{\mathrm{c} P} \leq 0.00 \mathrm{I}$; ${ }^{d} \mathrm{P}=0.054$.

Abbreviations: BMI, body mass index; CRP, C-reactive protein; ESR erythrocyte sedimentation rate; FBS, fasting blood sugar; WBC, white blood cells. 
ESR levels decreased significantly in the groups $\mathrm{C}$, E, and CE compared with baseline $(P \leq 0.05 P \leq 0.05, P \leq 0.001$, respectively). ESR levels in group CE was significantly lower than group $\mathrm{P}(\mathrm{P} \leq 0.05)$. Vitamin $\mathrm{E}$ was reported to regulate transcription or activity of a number of genes involved in oxidative stress, proliferation, inflammation, and apoptosis (Dutta and Dutta 2003; Tucker and Townsend 2005; Aldred et al 2006). CRP dropped in all groups in comparison with baseline, but this decreased more in group $\mathrm{E}(\mathrm{P}=0.054)$. The reduction of $\mathrm{WBC}$ in group $\mathrm{CE}$ was significant compare with other groups $(P<0.05)$ (Table 3$)$. PLT count decreased nonsignificantly in $\mathrm{CE}, \mathrm{C}, \mathrm{E}$ groups. Consequently CLAs, vitamin $\mathrm{E}$, and their combination are useful in reduction of inflammation. Many studies (Igarashi and Miyazawa 2001; Kim et al 2002; Palacios et al 2003; Bergamo et al 2006, 2007; Santos-Zago et al 2007) show the antioxidant effect of CLAs, but several studies performed on healthy and obese subjects have observed that CLAs administration is associated with an increase in some lipid oxidation and peripheral inflammation parameters (Riserus et al 2002, 2004; Basu et al 2000a, 2000b; Smedman et al 2004). One of our aims was to investigate the effect of $\alpha$-tocopherol and CLAs supplementation on BP. BP levels decreased significantly in the group $\mathrm{C}$ by $8 \%$ and $8.5 \%$ for DBP and MAP respectively, after three months of supplementation as compared with baseline. The reduction of SBP in group $\mathrm{C}$ was significant compared with the groups E and P (Table 2). Herrera and colleagues (2005) studied healthy primigravidas who had a family history of pre-eclampsia and diastolic notch. CalciumCLAs supplementation reduced significantly the incidence of pregnancy-induced hypertension (PIH) in the study group $(\mathrm{P}=0.01)$. Endothelial dysfunction was also significantly reduced after calcium-CLAs supplementation (Herrera et al 2005). Herrera and colleagues (2006) in another study on healthy primigravidas showed that the incidence of PIH was significantly reduced in women receiving the CLAs supplement compare with the placebo. There were no significant differences in the plasma concentrations of ionized calcium, PE2 (similar to our study), renin, angiotensin II, parathormone, and calcitonine (Herrera et al 2006). In Raff and colleagues' (2006) investigation, a diet rich in CLAs didn't alter SBP, DBP and pulse pressure, but this may be due to the short time for the study (five weeks). Nagao and colleagues (2003a) found that the relative mRNA expressions of angiotensinogen and leptin were suppressed by 10t, 12c-CLAs in adipose tissue. They speculate that the antihypertensive effect of $10 \mathrm{t}, 12 \mathrm{c}$-CLAs can be attributed to the lowered secretion of hypertensive adipocytokines from abdominal adipose tissues (Nagao et al 2003a). In another study Nagao and colleagues (2003b) showed that CLAs suppresses the development of nonobese essential hypertension in spontaneously hypertensive rats (SHRs). They concluded that the antihypertensive effect of dietary CLAs may be due to the increase of plasma adiponectin level and is associated with the alleviation of membrane abnormality in SHRs (Nagao et al 2003b). In our study in group E, BP increased nonsignificantly, in Ward and colleagues' (2007) study BP, pulse pressure, and heart rate increased versus placebo.

\section{Conclusion}

It is concluded that supplementation of $2 \mathrm{~g}$ CLAs 50:50 mix, and its combination with vitamin E for 12 weeks didn't change lipid profiles and FBS significantly, but CLAs decreased BP and vitamin E decreased CRP so co-supplementation of CLAs and vitamin E could be helpful for heart disease prevention in RA patients.

\section{Acknowledgments}

This study was funded through a research grant from the Research Deputy of Tehran University of Medical Sciences (with Proposal No., 2804). We appreciate the kind cooperation of both Lipid Nutrition Company (Nederland) for providing CLAs capsules as Clarinol G-80, and Zahravi Company (Iran) for providing vitamin E pearls for this research.

\section{References}

Aldred S, Sozzi T, Mudway I, et al. 2006. Alpha tocopherol supplementation elevates plasma apolipoprotein $\mathrm{A} 1$ isoforms in normal healthy subjects. Proteomics, 6:1695-703.

Alice V, da Costa V, Vianna LM. 2005. Effect of $\alpha$-tocopherol supplementation on blood pressure and lipidic profile in streptozotocininduced diabetes mellitus in spontaneously hypertensive rats. Clinica Chimica Acta, 351:101-4.

Arbonés-Mainar JM, Navarro MA, Guzmán MA, et al. 2006. Selective effect of conjugated linoleic acid isomers on atherosclerotic lesion development in apolipoprotein E knockout mice. Atherosclerosis, 189:318-27.

Arnett F, Edworthy SM, Bloch DA, et al. 1988. The American Rheumatoid Association 1987 revised criteria for the Classification of Rheumatoid Arthritis. Arthritis Rheum, 24:315-24.

Basu S, Smedman A, Vessby B. 2000b. Conjugated linoleic acid induces lipid peroxidation in humans. FEBS Lett, 468:33-6.

Basu S, Riserus U, Turpeinen A, et al. 2000a. Conjugated linoleic acid induces lipid peroxidation in men with abdominal obesity. Clin Sci (Lond), 99:511-6.

Belton OA, Duffy A, Toomey S, et al. 2003. Cyclooxygenase isoforms and platelet vessel wall interactions in the apolipoprotein E knockout mouse model of atherosclerosis. Circulation, 108:3017-23.

Benito P, Nelson GJ, Kelley DS, et al. 2001. The effect of conjugated linoleic acid on plasma lipoproteins and tissue fatty acid composition in humans. Lipids, 36:229-36. 
Bergamo P, Luongo D, Maurano F, et al. 2006. Conjugated linoleic acid enhances glutathione synthesis and attenuates pathological signs in MRL/MpJ-Fas(lpr) mice. J Lipid Res, 47:2382-91.

Bergamo P, Maurano F, Rossi M. 2007. Phase 2 enzyme induction by conjugated linoleic acid improves lupus-associated oxidative stress. Free Radic Biol Med, 43:71-9.

Bhattacharya A, Banu J, Rahman M, et al. 2006. Biological effects of conjugated linoleic acids in health and disease. J Nutr Biochem, 17:789-810.

Cywinski J. 1980. The Essentials in Pressure Monitoring. Boston, MA: Martinus Nijhoff, pp. 23-4.

De Pablo P, Dietrich T, Karlson EW. 2007. Antioxidants and other novel cardiovascular risk factors in subjects with rheumatoid arthritis in a large population sample. Arthritis Rheum, 57(Suppl 2):953-62.

Desroches S, Chouinard PY, Galibois I, et al. 2005. Lack of effect of dietary conjugated linoleic acids naturally incorporated into butter on the blood lipid profile and body composition of overweight and obese men. Am J Clin Nutr, 82:309-19.

Dessein PH, Stanwix AE, Joffe BI. 2002. Cardiovascular risk in rheumatoid arthritis versus osteoarthritis: acute phase response related decreased insulin sensitivity and high-density lipoprotein cholesterol as well as clustering of metabolic syndrome features in rheumatoid arthritis. Arthritis Res, 4(Suppl 5):R5.

Dutta A, Dutta SK. 2003. Vitamin E and its role in the prevention of atherosclerosis and carcinogenesis: a review. $J$ Am Coll Nutr, 22(Suppl 4):258-68.

Gavino VC, Gavino G, Leblanc MJ. 2000. An isomeric mixture of conjugated linoleic acids but not pure cis-9, trans-11-octadecadienoic acid affects body weight gain and plasma lipids in hamsters. $J$ Nutr, 130:27-9.

Gey KF, Moser UK, Jordan P, et al. 1993. Increased risk of cardiovascular disease at suboptimal plasma concentrations of essential antioxidants: an epidemiological update with special attention to carotene and vitamin C. Am J Clin Nutr, 57:787S-97S.

Gordon DJ, Probstfield JL, Garrison RJ, et al. 1989. High-density lipoprotein cholesterol and cardiovascular disease: four prospective American studies. Circulation, 79:8-15.

Hannawi S, Haluska B, Marwick TH, et al. 2007. Atherosclerotic disease is increased in recent-onset rheumatoid arthritis: a critical role for inflammation. Arthritis Res Ther, 9:R116.

Herrera JA, Arévalo-Herrera M, Shahabuddin AK, et al. 2006. Calcium and conjugated linoleic acid reduces pregnancy-induced hypertension and decreases intracellular calcium in lymphocytes. Am J Hypertens, 9(Suppl 4):381-7J.

Herrera JA, Shahabuddin GAKM, Ersheng C, et al. 2005. Calcium plus linoleic acid therapy for pregnancy-induced hypertension. Int $J$ Gynaecol Obstet, 91:221-7.

Houseknecht KL, Vanden JP, Moya-Camarena S, et al. 1998. Dietary conjugated linoleic acid normalises impared glucose tolerance in the Zucker diabetic fatty fa/fa rat. Biochem Biophys Res Commun, 244:678-82.

Igarashi M, Miyazawa T. 2001. The growth inhibitory effect of conjugated linoleic acid on a human hepatoma cell line, HepG2, is induced by a change in fatty acid metabolism, but not the facilitation of lipid peroxidation in the cells. Biochim Biophys Acta, 1530:162-71.

Jarvik GP, Hatsukami TS, Carlson C, et al. 2003. Paraoxonase activity, but not haplotype utilizing the linkage disequilibrium structure, predicts vascular disease. Arterioscler Thromb Vasc Biol, 23:1465-71.

Jarvik GP, Tsai NT, McKinstry LA, et al. 2002. Vitamin C and E intake is associated with increased paraoxonase activity. Arterioscler Thromb Vasc Biol, 22:1329-33

Jeon S-M, Park YB, Kwon O-S, et al. 2005. Vitamin E supplementation alters HDL-cholesterol concentration and paraoxonase activity in rabbits fed high-cholesterol diet: comparison with probucol. J Biochem Mol Toxicol, 19:336-46.

Kelly GS. 2001. Conjugated linoleic acid: A review. Altern Med Rev, 6:367-82.

Kim HK, Kim SR, Ahn JY, et al. 2002. Differential responses of hamsters and rats fed hig-fat or low-fat diets supplemented with conjugated linoleic acid. Nutr Res, 22:715-22.
Kim HK, Kim SR, Ahn JY, et al. 2005. Dietary conjugated linoleic acid reduces lipid peroxidation by increasing oxidative stability in rats. J Nutr Sci Vitaminol, 51(Suppl 1):8-15.

König B, Spielmann J, Haase K, et al. 2008. Effects of fish oil and conjugated linoleic acids on expression of target genes of PPARa and sterol regulatory element-binding proteins in the liver of laying hens. Br J Nutr, 21:1-9.

Kritchevsky D, Tepper SA, Wright S, et al. 2000. Influence of conjugated linoleic acid (CLAs) on establishment and progression of atherosclerosis in rabbits. J Am Coll Nutr, 19:472S-7S.

Kushi LH, Folsom AR, Prineas RJ, et al. 1996. Dietary antioxidant vitamins and death from coronary heart disease in postmenopausal women. N Engl J Med, 334:1156-62.

Lee KN, Kritchevsky D, Pariza MW. 1994. Conjugated linoleic acid and therosclerosis in rabbits. Atherosclerosis, 108:19-25.

Leonard SW, Joss JD, Mustacich DJ, et al. 2007. Effects of vitamin E on cholesterol levels of hypercholesterolemic patients receiving statins. Am J Health Syst Pharm, 64(Suppl 21):2257-66.

Lin Y, Schuurbiers E, van der Veen S, et al. 2001. Conjugated linoleic acid isomers have differential effects on triglyceride secretion in $\mathrm{HepG} 2$ cells. Biochim Biophys Acta, 1533:38-46.

Lowell BB. 1999. PPAR gamma: an essential regulator of adipogenesis and modulator of fat cell function. Cell, 99:239-42.

Metsios GS, Stavropoulos-Kalinoglou JAG, Veldhuijzen van Zanten J, et al. 2008. Rheumatoid arthritis, cardiovascular disease and physical exercise: a systematic review. Rheumatology, 47(Suppl 3):239-48.

Miyazaki M, Kim YC, Gray-Keller MP, et al. 2000. The biosynthesis of hepatic cholesterol esters and triglycerides is impaired in mice with a disruption of the gene for stearoyl-CoA desaturase 1. J Biol Chem, 275:30132-8.

Miyazaki M, Kim YC, Ntambi JM. 2001. A lipogenic diet in mice with a disruption of the stearoyl-CoA desaturase 1 gene reveals a stringent requirement of endogenous monounsaturated fatty acids for triglyceride synthesis. J Lipid Res, 42:1018-24.

Moya-Camarena SY, Belury MA. 1999a. Species differences in the metabolism and regulation of gene expression by conjugated linoleic acid. Nutr Rev, 57:336-40.

Moya-Camarena SY, Belury MA. 1999b. CLAs and PPARgamma activation. J Nutr, 129:602-6.

Moya-Carmarena SY, Vanden-Heuvel JP, Blanchard SG. 1999. Conjugated linoleic acid is a potent naturally occuring ligand and activator of PPARa. J Lipid Res, 40:1426-33.

Munday JS, Thompson KG, James KAC. 1999. Dietary conjugated linoleic acids promote fatty streak formation in the C57BL/6 mouse atherosclerosis model. Br J Nutr, 81:251-5.

Nagao K, Inoue N, Wang YM, et al. 2003a. The 10 trans, 12 cis isomer of conjugated linoleic acid suppresses the development of hypertension in Otsuka Long-Evans Tokushima fatty rats. Biochem Biophys Res Commun, 306:134-8.

Nagao K, Inoue N, Wang YM, et al. 2003b. Conjugated linoleic acid enhances plasma adiponectin level and alleviates hyperinsulinemia and hypertension in Zucker diabetic fatty (fa/fa) rats. Biochem Biophys Res Commun, 310:562-6.

Nicolosi RJ, Rogers EJ, Kritchevsky D, et al. 1997. Dietary conjugated linoleic acid reduces plasma lipoproteins and early aortic atherosclerosis in hypercholesterolemic hamsters. Artery, 22:266-77.

Nicolosi RJ, Woolfrey B, Wilson TA, et al. 2004. Decreased aortic early atherosclerosis and associated risk factors in hypercholesterolemic hamsters fed a high- or mid-oleic acid oil compared to a high-linoleic acid oil. J Nutr Biochem, 15:540-7.

Noone EJ, Roche HM, Nugent AP, et al. 2002. The effect of dietary supplementation using isomeric blends of conjugated linoleic acid on lipid metabolism in healthy human subjects. Br J Nutr, 88:243-51.

Ntambi JM. 1999. Regulation of stearoyl-CoA desaturase by polyunsaturated fatty acids and cholesterol. J Lipid Res, 40:1549-58.

Nurmohamed MT. 2007. Atherogenic lipid profiles and its management in patients with rheumatoid arthritis. Vasc Health Risk Manag, 3(Suppl 6):845-52. 
Pai JT, Guryev O, Brown MS, et al. 1998. Differential stimulation of cholesterol and unsaturated fatty acid biosynthesis in cells expressing individual nuclear sterol regulatory element-binding proteins. $J$ Biol Chem, 273:26138-48.

Palacios A, Piergiacomi V, Catalá A. 2003. Antioxidant effect of conjugated linoleic acid and vitamin A during non enzymatic lipid peroxidation of rat liver microsomes and mitochondria. Mol Cell Biochem, 250(Suppl 1-2):107-13.

Parodi PW. 1999. Conjugated linoleic acid and other anticarcinogenic agents of bovine milk fat. J Dairy Sci, 82:1339-49.

Peck LW, Nickel KP, Belury MA. 1998. Dietary conjugated linoleic acid normalizes impaired glucose tolerance in Zucker diabetic fatty fa/fa rat. Biochem Biophys Res Commun, 244:678-82.

Raff M, Tholstrup T, Sejrsen K, et al. 2006. Diets rich in conjugated linoleic acid and vaccenic acid have no effect on blood pressure and isobaric arterial elasticity in healthy young men. J Nutr, 136(Suppl 4):992-7.

Rainwater DL, Mahaney MC, VandeBerg JL, et al. 2007. Vitamin E dietary supplementation significantly affects multiple risk factors for cardiovascular disease in baboons. Am J Clin Nutr, 86:597-603.

Rimm EB, Stampfer MJ, Ascherio A, et al. 1993. Vitamin E consumption and the risk of coronary heart disease in men. New Engl J Med, 328:1450-6.

Riserus U, Arner P, Brismar K, et al. 2002. Treatment with dietary trans 10 cis12 conjugated linoleic acid causes isomer-specific insulin resistance in obese men with the metabolic syndrome. Diabetes Care, $25: 1516-21$

Riserus U, Berglund L, Vessby B. 2001. Conjugated linoleic acid (CLAs) reduced abdominal adipose tissue in obese middle-aged men with signs of the metabolic syndrome: a randomised controlled trial. Int J Obes Relat Metab Disord, 25:1129-35.

Roche HM, Noone E, Sewter C, et al. 2002. Isomer-dependent metabolic effects of conjugated linoleic acid: insights from molecular markers sterol regulatory element-binding protein-1c and LXRalpha. Diabetes, 51:2037-44.

Rudel LL. 1999. Atherosclerosis and conjugated linoleic acid. Br J Nutr, $81: 177-9$

Santos-Zago LF, Botelho AP, de Oliveira AC. 2007. Supplementation with commercial mixtures of conjugated linoleic acid in association with vitamin $\mathrm{E}$ and the process of lipid autoxidation in rats. Lipids, 42:845-54.

Sanz DC, Santa-Cruz MC. 1986. Simultaneous measurement of retinol and $\alpha$-tocopherol in human serum by high-performance liquid chromatography with ultraviolet detection. J Chromatogr, 380:140-4.

Schwenke DC, Behr SR. 1998. Vitamin E combined with selenium inhibits atherosclerosis in hypercholesterolemic rabbits independently of effects on plasma cholesterol concentrations. Circ Res, 83:366-77.

Singh AU, Devaraj S, Jialal I. 2005. Vitamin E, oxidative stress, and inflammation. Annu Rev Nutr, 25:151-74.
Singhal S, Gupta R, Goyle A. 2001. Comparison of antioxidant efficacy of vitamin $\mathrm{E}$, vitamin $\mathrm{C}$, vitamin $\mathrm{A}$ and fruits in coronary heart disease: a controlled trial. J Assoc Physicians India, 49:327-31.

Smedman A, Vessby B, Basu S. 2004. Isomer-specific effects of conjugated linoleic acid on lipid peroxidation in humans: regulation by alpha-tocopherol and cyclo-oxygenase-2 inhibitor. Clin Sci (Lond), 106:67-73.

Smedman A, Vessby B. 2001. Conjugated linoleic acid supplementation in humans metabolic effects. Lipids, 36:773-8.

Stampfer MJ, Hennekens CH, Manson JE, et al. 1993. Vitamin E consumption and the risk of coronary disease in women. New Engl J Med, 328:1444-9.

Stangl GI. 2000. High dietary levels of conjugated linoleic acid mixture alter hepatic glycerophospholipid CLAss profile and cholesterol-carrying serum lipoproteins of rats. J Nutr Biochem, 11:184-91.

Stephens NG, Parsons A, Schofield PM, et al. 1996. Randomised controlled trial of vitamin $\mathrm{E}$ in patients with coronary disease: Cambridge Heart Antioxidant Study (CHAOS). Lancet, 347:781-6.

Taylor CG, Zahradka P. 2004. Dietary conjugated linoleic acid and insulin sensitivity and resistance in rodent models. Am J Clin Nutr, 79(Suppl 6):1164S-1168S.

Toomey S, Roche H, Fitzgerald D, et al. 2003. Regression of pre established atherosclerosis in the apo $\mathrm{E}^{-/}$mouse by conjugated linoleic acid. Biochem Soc Trans, 31:1075-9.

Tricon S, Burdge GC, Kew S, et al. 2004. Opposing effects of cis-9, trans-11 and trans-10, cis-12 conjugated linoleic acid on blood lipids in healthy humans. Am J Clin Nutr, 80:614-20.

Truitt A, McNeill G, Vanderhoek JY. 1999. Antiplatelet effects of conjugated linoleic acid isomers. Biochim Biophys Acta, 1438:239-46.

Tsuboyama-Kasaoka N, Takahashi M, Tanemura K, et al. 2000. Conjugated linoleic acid supplementation reduces adipose tissue by apoptosis and develops lipodystrophy in mice. Diabetes, 49(Suppl 9):1534-42.

Tucker JM, Townsend DM. 2005. Alpha-tocopherol: roles in prevention and therapy of human disease. Biomed Pharmacother, 59:380-7.

Valeille K, Férézou J, Amsler G, et al. 2005. A cis-9, trans-11-conjugated linoleic acid-rich oil reduces the outcome of atherogenic process in hyperlipidemic hamster. Am J Physiol Heart Circ Physiol, 289:H652-H659.

Ward NC, Wu JH, Clarke MW, et al. 2007. The effect of vitamin E on blood pressure in individuals with type 2 diabetes: a randomized, double-blind, placebo-controlled trial. $J$ Hypertens, 25:227-34.

Wilson TA, Nicolosi RJ, Chrysam M, et al. 2000. Conjugated linoleic acid reduces early aortic atherosclerosis greater than linoleic acid in hypercholesterolemic hamsters. Nutr Res, 20:1795-805.

Zambell KL, Keim NL, Van Loan MD, et al. 2000. Conjugated linoleic acid supplementation in humans: effects on body composition and energy expenditure. Lipids, 35:777-82. 